Int. J. Electrochem. Sci., 14 (2019) $8405-8418$

International Journal of

ELECTROCHEMICAL

SCIENCE

WWW.electrochemsci.org

\title{
Rose, Gardenia, and Solanum Violaceum Extracts as Inhibitors of Steel Corrosion
}

\author{
Xia Wang ${ }^{1 *}, Y u e ~ G u^{1^{*}}$, Qiao Zhang ${ }^{1}$, Linglong X ${ }^{1}$, Xiong Li $^{1}$ \\ School of Material Science and Engineering, Southwest Petroleum University, Chengdu, Sichuan \\ *E-mail: swpi_wx@126.com, 2871765615@qq.com \\ doi: $10.20964 / 2019.09 .41$
}

Received: 30 April 2019 / Accepted: 3 July 2019 / Published: 31 July 2019

\begin{abstract}
To explore the application of environmentally friendly metal corrosion inhibitors, we made extracts of three kinds of plant corrosion inhibitors, and we explored ways to improve their corrosion inhibition efficiency. We used the weight loss method to study the corrosion inhibition of mild steel in $1 \mathrm{M} \mathrm{HCl}$ solutions, using extracts of rose, gardenia, and Solanum violaceum. We found that the extracts acted as effective corrosion inhibitors for mild steel in an acidic medium. The inhibition process was attributed to the formation of an adsorbed film of inhibitor on the metal surface that protected the metal against corrosion. We determined by Fourier infrared spectroscopy that the $\mathrm{N}-\mathrm{H}, \mathrm{C}=\mathrm{N}$, and C-O functional groups in the three plant extracts were important is this corrosion inhibition. The inhibition efficiency $(\% \mathrm{E})$ of the extracts increased with increasing inhibitor concentration but decreased with increasing temperature. Using electrochemical methods, we found that the three plant corrosion inhibitors researched are all mixed corrosion inhibitors, which have inhibitory effects on both the cathodic and anodic reaction processes. Mixtures of (1) gardenia blossom inhibitor (GD) with rose extract inhibitor (RE) and (2) Solanum violaceum inhibitor (SV) with RE had synergistic effect factors less than one, which implied that the synergistic effect was great, and that the efficiency of a single plant inhibitor RE was improved by mixing with other inhibitors.
\end{abstract}

Keywords: Plant corrosion inhibitor; gardenia; rose; Solanum violaceum

\section{$\underline{\text { FULL TEXT }}$}

(C) 2019 The Authors. Published by ESG (www.electrochemsci.org). This article is an open access article distributed under the terms and conditions of the Creative Commons Attribution license (http://creativecommons.org/licenses/by/4.0/). 